\title{
The influences of bariatric surgery on hemoglobin Alc in a sample of obese patients in Saudi Arabia
}

\author{
Anwar E Ahmed ${ }^{1,2}$ \\ Wala R Alanazi ${ }^{3}$ \\ Rayan A Ahmed ${ }^{4}$ \\ Wijdan AlJohi ${ }^{2}$ \\ Doaa A AlBuraikan ${ }^{2}$ \\ Budor A AIRasheed ${ }^{2}$ \\ Bashayr I ALMuqbil ${ }^{2}$ \\ Ali A Al-Zahrani ${ }^{2,5}$ \\ Zeyad M Yousef ${ }^{2,5}$ \\ Hamdan AL-Jahdali ${ }^{2,5}$ \\ 'King Abdullah International Medical \\ Research Center (KAIMRC), Riyadh, \\ Saudi Arabia; ${ }^{2}$ King Saud bin Abdulaziz \\ University for Health Sciences, Riyadh, \\ Saudi Arabia; ${ }^{3} \mathrm{Al}-$ Maarefa College for \\ Science and Technology, Riyadh, Saudi \\ Arabia; ${ }^{4}$ Dar Al Uloom University, \\ Riyadh, Saudi Arabia; ${ }^{5}$ King Abdulaziz \\ Medical City, Riyadh, National Guard \\ Health Affairs, Riyadh, Saudi Arabia
}

Correspondence: Anwar E Ahmed College of Public Health and Health Informatics, King Saud bin Abdulaziz University for Health Sciences, MC 2350, P.O. Box 22490, Riyadh II426, Saudi Arabia

Tel +966 II 80 I I II I ext 954I5

Email ahmeda5@vcu.edu
This article was published in the following Dove Press journal: Diabetes, Metabolic Syndrome and Obesity:Targets and Therapy

Background: Although the frequency of surgical weight loss interventions has increased in Saudi Arabia, literature describing the clinical outcomes of bariatric surgery in Saudi Arabia is limited. This study aimed to assess whether weight loss intervention improves hemoglobin $\mathrm{A} 1 \mathrm{c}(\mathrm{HbA1c})$ in obese patients and to identify its associated factors.

Patients and methods: A retrospective study was carried out on 318 patients with obesity class 1 or higher (body mass index $[\mathrm{BMI}] \geq 30 \mathrm{~kg} / \mathrm{m}^{2}$ ) who underwent laparoscopic sleeve gastrectomy or Roux-en-Y gastric bypass at King Abdulaziz Medical City in Riyadh, Saudi Arabia, between January 1, 2001 and March 31, 2017. Preoperatively and 12 months postoperatively, characteristics of patients were collected. BMI reduction was calculated, based on which patients were divided into three groups $\left(0-9,10-14\right.$, and $\left.>14 \mathrm{~kg} / \mathrm{m}^{2}\right)$.

Results: The postoperative HbA1c was $5.83 \pm 0.9$, while the baseline level was $6.74 \pm 2.1$ $(P=0.001)$. Fifty-eight of the 318 patients had diabetes. We observed significantly higher $\mathrm{HbA1c}$ in diabetic than in non-diabetic patients preoperatively, whereas an insignificantly different HbA1c was observed postoperatively. Among those who had minimal reduction in BMI (0-9 kg/m²), we observed significantly higher HbA1c in diabetic than in nondiabetic patients, whereas among those who had large reduction in BMI $\left(10-14 \mathrm{~kg} / \mathrm{m}^{2}\right)$ and $\left(>14 \mathrm{~kg} / \mathrm{m}^{2}\right)$, we observed insignificant differences in $\mathrm{HbA} 1 \mathrm{c}$ in diabetic than in non-diabetic patients.

Conclusion: Being a diabetic patient was related to a significant reduction in $\mathrm{HbA} 1 \mathrm{c}$ levels postoperatively. The study suggests that the reduction in HbA1c levels could be modified by BMI, wherein greater reduction in BMI leads to greater reduction in HbAlc levels.

Keywords: HbA1c, diabetes, weight loss surgery, BMI, morbid obese, sleeve

\section{Introduction}

Obesity is a major public health challenge in Saudi Arabia because it can pose serious health-related issues. ${ }^{1,2}$ In fact, its high prevalence has been projected as $41 \%$ in males and $78 \%$ in females by $2022 .{ }^{3}$ It has been associated with a number of noncommunicable diseases, ${ }^{4}$ which are responsible for increasing the rate of mortality in the Saudi population. ${ }^{5}$ With the increased obesity prevalence in Saudi Arabia, weight loss or bariatric surgeries are becoming the most popular and effective surgical interventions in patients with obesity.

In addition to investigating substantial weight loss, several international studies have explored the associations between weight loss results from the surgical interventions and long-term health benefits such as reduction of underlying medical conditions 
among morbidly obese patients. ${ }^{6-19}$ For instance, earlier reports investigated the effectiveness of weight loss after bariatric surgery in achieving optimal glycemic control. ${ }^{9-19}$ According to these studies, bariatric procedures could be effective therapeutic interventions in morbidly obese patients with diabetes. However, a few other studies reported bariatric surgery may not necessarily correlate with optimal glycemic control..$^{20,21}$

The health benefits of bariatric procedures in diabetes patients are well documented in several international studies. It has been reported that laparoscopic sleeve gastrectomy (LSG) in diabetic patients with obesity may be effective in achieving optimal glycemic control. ${ }^{14-19}$ Other studies reported that LSG and Roux-en-Y gastric bypass (RYGB) lead to similar improvements in plasma glucose homeostasis, insulin sensitivity, and beta-cell function in non-diabetic obese people. ${ }^{12,13}$

Despite the fact that bariatric surgery confirmed improved patient clinical outcome by reducing the risk of potential weight-related health problems, our understanding of the health benefits of bariatric surgery in Saudi Arabia has not yet been documented, specifically in diabetic patients. Two studies in Saudi Arabia focused only on weight reduction and one on a surgical option, which is sleeve gastrectomy. ${ }^{22,23}$ Another study compared weight reduction, complications, and quality of life in patients who underwent one of three surgical procedures - LSG, RYGB, and laparoscopic adjustable gastric banding. ${ }^{24}$ No evidence is available on the impact of the bariatric surgery on glycemic control status (i.e., hemoglobin A1c [HbA1c]) in the Saudi population.

Recently, Ahmed et al, in a study conducted at King Abdulaziz Medical City in Riyadh, reported a hospital readmission rate of $8 \%$ and an emergency department visit rate of $14 \%$ in obese Saudi patients who underwent bariatric surgery. ${ }^{25}$ According to this study, LSG was associated with fewer hospital readmissions or emergency department visits as compared to RYGB.

To date, the effectiveness of bariatric surgery has not been assessed in Saudi Arabia to obtain optimal glycemic control. Such studies on the Saudi Arabian population would be of international interest. The hypotheses of the study are the following: there is a statistically significant reduction in the $\mathrm{HbA} 1 \mathrm{c}$ over a 1 -year period after surgery among patients with diabetes. The study aimed to 1) assess whether bariatric surgery improves $\mathrm{HbA} 1 \mathrm{c}$ in obese patients and 2) identify its associated factors in Saudi Arabia.

\section{Patients and methods}

The authors retrospectively studied 318 patients with obesity class 1 or higher BMI ( $\left.\geq 30 \mathrm{~kg} / \mathrm{m}^{2}\right)$, who underwent either bariatric surgery LSG or RYGB at King Abdulaziz Medical City in Riyadh, Saudi Arabia, between January 1, 2001 and March 31, 2017. The study was approved by the Institutional Review Board at King Abdullah International Medical Research Center, Riyadh, Saudi Arabia (RC17/138/R). Patient consent to review their medical records was not required by the Institutional Review Board at King Abdullah International Medical Research Center. This study involves the use of existing information with no patient-related care responsibilities. No identifier was used, and the privacy and confidentiality of patients were completely protected.

Data for this study were retrieved from the collected medical records. The baseline and clinical characteristics included information such as age, sex, BMI $\left(\mathrm{kg} / \mathrm{m}^{2}\right)$, diabetes (Yes/ No), asthma (Yes/No), obstructive sleep apnea (Yes/No), and procedure type (LSG/RYGB). The authors evaluated surgery outcomes in the study population. Available BMI and/or $\mathrm{HbA} 1 \mathrm{c}$ readings were reviewed for patients who had visited our center and these measurements were only considered if they occurred within a period of 12 months after the surgery. In the case of multiple readings, the most recent reading was selected and recorded. Differences between the preoperative visit and postoperative visit were calculated for each reading of BMI, and HbA1c. Percent reduction was calculated for $\mathrm{BMI}$ and $\mathrm{HbAl} \mathrm{c}$ using the formula (postoperative - preoperative)/preoperative $\times 100 \%$. Also, for the purpose of the analysis, BMI reduction was classified into three groups: reduction of $9 \mathrm{~kg} / \mathrm{m}^{2}$ or less, reduction between 10 and $14 \mathrm{~kg} / \mathrm{m}^{2}$, and reduction of $>14 \mathrm{~kg} / \mathrm{m}^{2}$. As per the criteria of the American Diabetes Association, the authors used $\mathrm{HbA} 1 \mathrm{c} \leq 6.5 \%$ as the definition of achieving optimal HbA1c.

\section{Statistical analyses}

Statistical analyses were performed using SAS V 9.4 (SAS Institute, Cary, NC, USA). Categorical patient characteristics were expressed as frequency and percent, while continual patient characteristics were expressed as mean and SD. Paired sample $t$-tests were used to test differences in $\mathrm{HbAlc}$ in the whole sample $(\mathrm{N}=318)$. Furthermore, paired sample $t$-tests were used to assess the differences in $\mathrm{HbAlc}$ before and after the surgery, separately, and in the diabetic group and non-diabetic group. The effects of visit (pre- and postoperative) on HbAlc were also assessed. We assessed the impact of diabetes, BMI reduction, and visit on lowering $\mathrm{HbA1c}$ 
after the surgery, controlling the patient characteristics. A multivariate mixed-effects model was used to identify the interaction terms that were associated with lowering HbAlc. The following interaction terms were examined: (diabetes $\times$ visit), (diabetes $\times$ BMI reduction), and (procedure type $\times$ visit). Moreover, multiple comparisons were performed using the Tukey for significant interactions terms.

\section{Results}

The sample included 318 obese subjects who underwent surgical weight loss intervention (LSG or RYGB) during the study period. The baseline characteristics of the sample with obesity are shown in Table 1 . The mean age was 34.7 years with an SD of 11.7 years, and the age ranged between 13 and 64 years. The mean of baseline BMI was $46.8 \mathrm{~kg} / \mathrm{m}^{2}$ with an $\mathrm{SD}$ of $7.7 \mathrm{~kg} / \mathrm{m}^{2}$, and the BMI ranged between 32.7 and 83 $\mathrm{kg} / \mathrm{m}^{2}$. The mean HbAlc at baseline was 6.7 with an SD of 2.1, and $\mathrm{HbA} 1 \mathrm{c}$ ranged between 2.5 and 14 . The majority of patients $(67.6 \%)$ were females, and $88.4 \%$ underwent LSG. Of the sample, $18.4 \%$ had diabetes, $13.9 \%$ had asthma, and $7.9 \%$ had obstructive sleep apnea.

Paired sample $t$-test showed significant reduction in HbA1c in the whole sample $(\mathrm{N}=318)$ from pre- to postoperative $(6.74 \pm 2.1$ preoperative vs. $5.83 \pm 0.9$ postoperative, $P=0.001)$. This analysis was stratified further by the diabetic status: we noted significantly greater reduction in $\mathrm{HbA} 1 \mathrm{c}$ from pre- to postoperative $(8.5 \pm 2.4$ preoperative vs. $6.3 \pm 1.0$ postoperative, $P=0.001)$ in the diabetes group and slight but significant reduction in $\mathrm{HbAlc}(5.7 \pm 0.7$ preoperative vs.

Table I Patient characteristics $(\mathrm{N}=3 \mid 8)$

\begin{tabular}{|c|c|c|c|}
\hline Characteristics & Levels & $\mathbf{n}$ & $\%$ \\
\hline \multirow[t]{2}{*}{ Sex } & Female & 215 & 67.6 \\
\hline & Male & 103 & 32.4 \\
\hline \multirow[t]{2}{*}{ Bariatric procedure } & RYGB & 37 & 11.6 \\
\hline & LSG & 281 & 88.4 \\
\hline \multirow[t]{2}{*}{ Diabetes } & No & 258 & 81.6 \\
\hline & Yes & 58 & 18.4 \\
\hline \multirow[t]{2}{*}{ Asthma } & No & 272 & 86.1 \\
\hline & Yes & 44 & 13.9 \\
\hline \multirow[t]{2}{*}{ Obstructive sleep apnea } & No & 291 & 92.1 \\
\hline & Yes & 25 & 7.9 \\
\hline \multirow[t]{4}{*}{$\mathrm{BMI}$ reduction, kg/m² } & $0-9$ & 113 & 43.0 \\
\hline & $10-14$ & 68 & 25.9 \\
\hline & $>14$ & 82 & $3 I .1$ \\
\hline & & Mean & $\pm \mathrm{SD}$ \\
\hline Age (13-64), years & & 34.7 & 11.7 \\
\hline Baseline BMI (32.7-83.I), kg/m² & & 46.8 & 7.7 \\
\hline Baseline HbA Ic (2.5-I4), \% & & 6.7 & 2.1 \\
\hline
\end{tabular}

$5.4 \pm 0.5$ postoperative, $P=0.001$ ) in the non-diabetic group. This resulted in a reduction of $25.9 \%$ in the diabetic group and $5.3 \%$ in non-diabetic group. The individual changes in $\mathrm{HbA} 1 \mathrm{c}$ after surgery can be found in Figure 1A. The waterfall plot shows that the procedure was associated with greater $\mathrm{HbA1c}$ reduction in patients with diabetes than in those without diabetes. Postoperatively, the HbA1c target of $6.5 \%$ or below was met in $62.5 \%$ of the diabetic group and $97.1 \%$ of the non-diabetic group.

Analysis with the multivariate mixed model showed that there were insignificant differences in HbA1c by demographic characteristics: age and sex. The model demonstrated significant diabetes by visits interaction effects $(P=0.001)$. According to Tukey multiple comparisons, diabetic patients had significantly higher HbAlc than non-diabetic patients at the baseline, whereas diabetic patients had insignificantly higher $\mathrm{HbA} 1 \mathrm{c}$ than non-diabetic patients following the surgical procedure (Figure 1B).

We found significant interaction effects between diabetes by $B M I$ reduction $\left(10-14 \mathrm{~kg} / \mathrm{m}^{2}[P=0.012]\right.$ and $>14 \mathrm{~kg} / \mathrm{m}^{2}$ $[P=0.003])$ on $\mathrm{HbA} 1 \mathrm{c}$. In those who had minimal reduction in BMI (0-9 kg/m²), we observed significantly higher HbA1c levels in diabetic patients than in non-diabetic patients. In those who had greater reduction in BMI (10-14 and >14 kg/ $\mathrm{m}^{2}$ ), we observed insignificant differences in HbA1c levels in diabetic patients than in non-diabetic patients (Figure 1C).

Results of the mixed-effects model analysis presented in Table 2 indicate significant interaction effects between procedure type-by-visit $(P=0.018)$ on HbA1c. There was significant difference in $\mathrm{HbA} 1 \mathrm{c}$ within the LSG and RYGB groups between baseline and following the surgical procedure, while there was insignificant difference between the LSG and RYGB groups in the HbAlc preoperatively and postoperatively (Figure 1D).

\section{Discussion}

The literature describing the clinical outcomes of surgical weight loss interventions in Saudi Arabia is limited, particularly regarding the $\mathrm{HbA} 1 \mathrm{c}$ parameter. In this study, we retrospectively gathered data on patients with obesity class I or higher $\left(\mathrm{BMI} \geq 30 \mathrm{~kg} / \mathrm{m}^{2}\right.$ ) who underwent LSG and RYGB at King Abdulaziz Medical City in Riyadh, Saudi Arabia, between January 1, 2001 and March 31, 2017. The surgical weight loss interventions appear to have had a large effect on the $\mathrm{HbA} 1 \mathrm{c}$ parameter within a short term, that is, a period of 12 months after the surgery.

In a period of 12 months postoperatively, the HbA1c target of $6.5 \%$ or below was met in $62.5 \%$ of the diabetic 
A

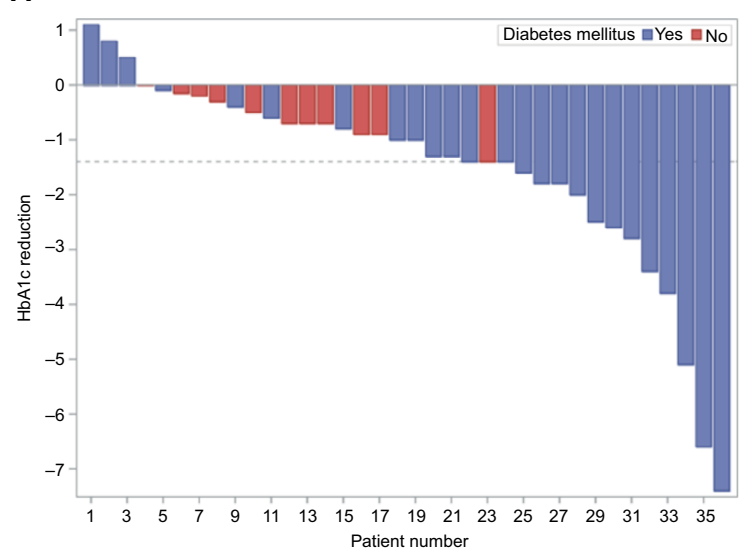

C

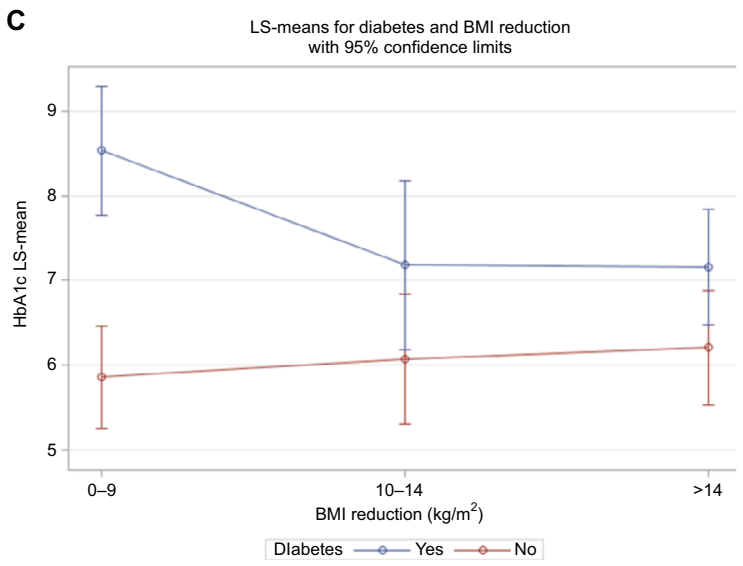

B

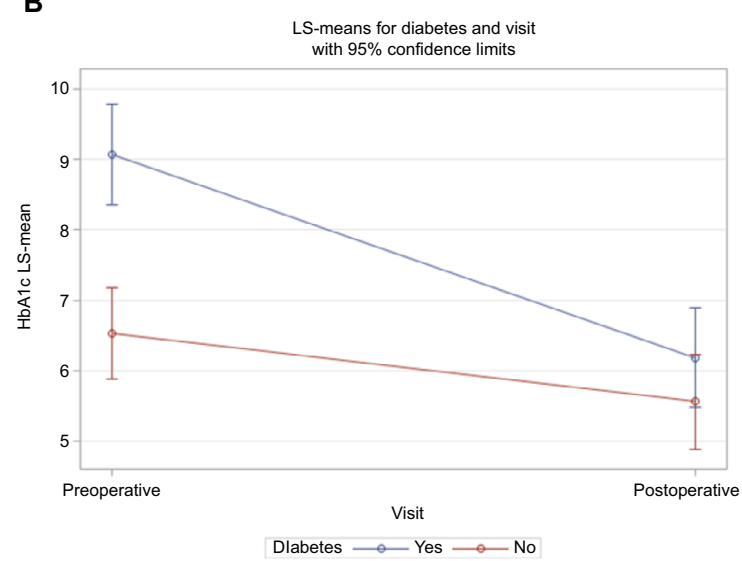

D

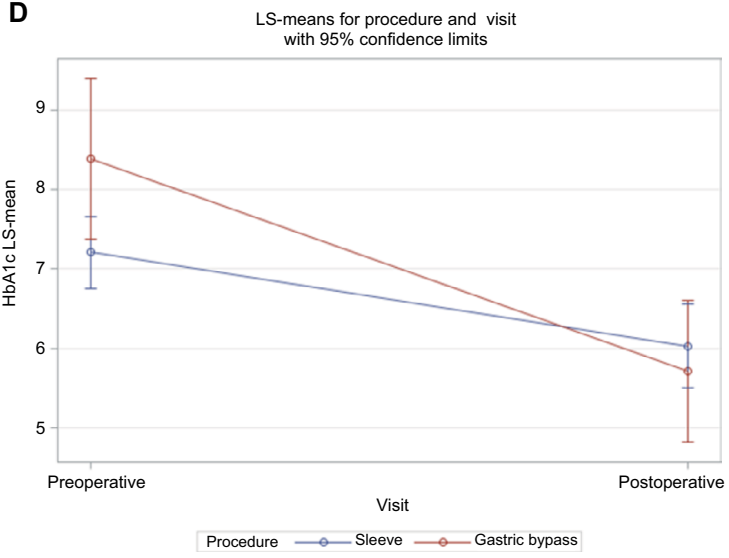

Figure I Changes in $\mathrm{HbAlc}$ by visit, diabetes status, body mass index $\left(\mathrm{kg} / \mathrm{m}^{2}\right)$ reduction, and procedure type after bariatric surgery.

Notes: (A) We observed significantly greater reduction in $\mathrm{HbAlc}$ in patients with diabetes than those without diabetes. (B) Diabetic patients had significantly higher $\mathrm{HbAlc}$ than non-diabetic patients at the baseline, whereas diabetic patients had insignificantly higher HbAlc than non-diabetic patients following the surgical procedure. (C) In those who had greater reduction in BMI (I0-14 and $\left.>14 \mathrm{~kg} / \mathrm{m}^{2}\right)$, we observed insignificant differences in HbAlc levels between diabetic patients and non-diabetic patients. (D) There was a significant difference in HbAlc within the LSG and RYGB groups between baseline and following the surgical procedure, while there was insignificant difference between the LSG and RYGB groups in the HbAIc preoperatively and postoperatively.

Abbreviations: BMI, body mass index; HbAIc, hemoglobin Alc; LS-means, least squares-means.

Table 2 Factors associated with the change in HbAlc using mixed-effects model

\begin{tabular}{|c|c|c|c|c|}
\hline & B & SE & $t$-value & $P$-value \\
\hline Intercept & 6.343 & $0.65 I$ & 9.740 & 0.001 \\
\hline \multicolumn{5}{|l|}{ Main effects } \\
\hline Age & 0.013 & 0.010 & 1.300 & 0.206 \\
\hline Female & -0.194 & 0.240 & -0.810 & 0.426 \\
\hline LSG & -1.181 & 0.486 & -2.430 & $0.022 *$ \\
\hline Diabetes & 3.628 & 0.406 & 8.940 & $0.001 *$ \\
\hline Asthma & -0.390 & 0.305 & -1.280 & 0.212 \\
\hline Obstructive sleep apnea & 0.697 & 0.410 & 1.700 & 0.100 \\
\hline Postoperative visit & -1.717 & 0.598 & -2.870 & $0.008^{*}$ \\
\hline BMI reduction $10-14 \mathrm{~kg} / \mathrm{m}^{2}$ & 0.210 & 0.329 & 0.640 & 0.528 \\
\hline BMI reduction $>14 \mathrm{~kg} / \mathrm{m}^{2}$ & 0.349 & 0.333 & 1.050 & 0.304 \\
\hline \multicolumn{5}{|l|}{ Interaction effects } \\
\hline Diabetes $\times$ postoperative visit & -1.911 & 0.393 & -4.860 & $0.001 *$ \\
\hline Diabetes $\times \mathrm{BMI}$ reduction $10-14 \mathrm{~kg} / \mathrm{m}^{2}$ & -1.560 & 0.580 & -2.690 & $0.012 *$ \\
\hline Diabetes $\times \mathrm{BMI}$ reduction $>14 \mathrm{~kg} / \mathrm{m}^{2}$ & -1.717 & 0.528 & -3.250 & $0.003 *$ \\
\hline LSG $\times$ postoperative visit & 1.497 & 0.596 & 2.510 & $0.018^{*}$ \\
\hline
\end{tabular}

Note: *Significant at $\alpha=0.05$.

Abbreviations: BMI, body mass index; HbAlc, hemoglobin Alc; LSG, laparoscopic sleeve gastrectomy; SE, standard error. patients and $97.1 \%$ of the non-diabetic patients. This can be compared with patients who were on HbAlc target of $6.5 \%$ or below at baseline or prior to the procedure: $25.71 \%$ of the diabetic patients and $91.8 \%$ of the non-diabetic patients. Similar findings are found in reports from various international regions and with different follow-up periods, where they have shown rapid improvement in glycemic control after bariatric surgery. ${ }^{9-19}$ Thus, our data provide strong evidence for the effectiveness of bariatric surgery in improving $\mathrm{HbAlc}$ in a Saudi sample of patients in whom optimal HbAlc has not been investigated. Future research studies are needed to assess the effectiveness of weight reduction in treating obese patients with other comorbidities.

The uniqueness of the current study is that we were able to link the reduction in $\mathrm{HbAlc}$ to the diabetic status and to the reduction in BMI. For instance, at baseline, we noted significantly higher $\mathrm{HbA} 1 \mathrm{c}$ in diabetic patients than in non-diabetic patients, whereas postoperatively, insignificant 
differences were noted between diabetes patients and nondiabetes patients. The reduction in HbAlc levels in our study can be explained by diabetes and the greater reduction in BMI. Among those who had minimal reduction in BMI $\left(0-9 \mathrm{~kg} / \mathrm{m}^{2}\right)$, we observed significantly higher HbA1c levels in diabetic patients than in non-diabetic patients, whereas among those who had a large reduction in BMI $\left(10-14 \mathrm{~kg} / \mathrm{m}^{2}\right)$ and $\left(>14 \mathrm{~kg} / \mathrm{m}^{2}\right)$, we observed insignificant differences in HbA1c levels in diabetic patients than in non-diabetic patients. These findings were similar to a number of previous international reports, ${ }^{26-29}$ in which weight reduction led to a significant improvement of glycemic control in diabetic patients who underwent bariatric surgery.

Although we noted significant reduction in $\mathrm{HbA} 1 \mathrm{c}$ within the LSG and RYGB groups between preoperative and postoperative periods, in agreement with our analysis results, ${ }^{30,31}$ both LSG and RYGB had a similar effect on the reduction of HbA1c levels postoperatively. LSG seems to be a promising weight loss procedure in our center, as $88.4 \%$ of our patients underwent this procedure. A long-term longitudinal study is needed to compare and evaluate the effectiveness of these procedures in achieving early optimal glycemic control after surgery.

The current study was limited by its nature, that is, retrospective chart review, as not all data were available during the 12-month period after surgery. We did not retrieve data on the types and dose of insulin prescribed to diabetes patients. Data were collected only preoperatively and postoperatively, rather than by using multiple records: baseline, 3, 6, and 12 months. Despite these limitations, the study findings represent preliminary highlights of the clinical outcomes of bariatric surgery on achieving optimal glycemic control in Saudi Arabia, as none of the studies have evaluated metabolic comorbidities in this population.

\section{Conclusion}

A significant reduction in $\mathrm{HbA} 1 \mathrm{c}$ levels at postoperative was noted in diabetic patients. The study suggests that reduction in $\mathrm{HbA} 1 \mathrm{c}$ levels could be modified by BMI, wherein greater reduction in BMI leads to greater reduction in $\mathrm{HbA} 1 \mathrm{c}$ levels. Large longitudinal studies on the long-term clinical outcomes of the surgical weight loss interventions are warranted, specifically assessing remission of other comorbidities that are related to obesity.

\section{Acknowledgment}

We would like to thank King Abdullah International Medical Research Center, Riyadh, Saudi Arabia, for approving the study.

\section{Disclosure}

The authors report no conflicts of interest in this work.

\section{References}

1. Baslaim G, Bashore J, Alhoroub K. Impact of obesity on early outcomes after cardiac surgery: experience in a Saudi Arabian center. Ann Thorac Cardiovasc Surg. 2008;14(6):369-375.

2. Al-Hazzaa HM. Prevalence and trends in obesity among school boys in Central Saudi Arabia between 1988 and 2005. Saudi Med J. 2007;28(10):1569-1574.

3. Al-Quwaidhi AJ, Pearce MS, Critchley JA, Sobngwi E, O'Flaherty $M$. Trends and future projections of the prevalence of adult obesity in Saudi Arabia, 1992-2022/Tendances et projections de la prévalence de l'obésité chez l'adulte en Arabie saoudite, 1992-2022. East Mediterr Health J. 2014;20(10):589-595.

4. Al-Daghri NM, Alkharfy KM, Al-Attas OS, et al. Association between type 2 diabetes mellitus-related SNP variants and obesity traits in a Saudi population. Mol Biol Rep. 2014;41(3):1731-1740.

5. Aldawood A, Arabi Y, Dabbagh O. Association of obesity with increased mortality in the critically ill patient. Anaesth Intensive Care. 2006;34(5):629-633.

6. Sudan R, Nguyen NT, Hutter MM, Brethauer SA, Ponce J, Morton JM. Morbidity, mortality, and weight loss outcomes after reoperative bariatric surgery in the USA. J Gastrointest Surg. 201519(1): 171-179.

7. Herman KM, Carver TE, Christou NV, Andersen RE. Keeping the weight off: physical activity, sitting time, and weight loss maintenance in bariatric surgery patients 2 to 16 years postsurgery. Obes Surg. 2014;24(7):1064-1072.

8. Douglas IJ, Bhaskaran K, Batterham RL, Smeeth L. Bariatric surgery in the United Kingdom: a cohort study of weight loss and clinical outcomes in routine clinical care. PLoS Med. 2015;12(12): e1001925.

9. le Roux CW, Aylwin SJ, Batterham RL, et al. Gut hormone profiles following bariatric surgery favor an anorectic state, facilitate weight loss, and improve metabolic parameters. Ann Surg. 2006;243(1): $108-114$.

10. Caballero MA, Jiménez JM, Castro MJ, Solórzano JO, Arango A. Outcomes in weight loss, fasting blood glucose and glycosylated hemoglobin in a sample of 415 obese patients, included in the database of the European accreditation council for excellence centers for bariatric surgery with laparoscopic one anastomosis gastric bypass. Nutrición hospitalaria: Organo oficial de la Sociedad española de nutrición parenteral y enteral. 2014;30(5):1032-1038.

11. Abegg K, Corteville C, Docherty NG, et al. Effect of bariatric surgery combined with medical therapy versus intensive medical therapy or calorie restriction and weight loss on glycemic control in Zucker diabetic fatty rats. Am J Physiol Regul Integr Comp Physiol. 2015;308(4): R321-R329.

12. Bradley D, Magkos F, Eagon JC, et al. Matched weight loss induced by sleeve gastrectomy or gastric bypass similarly improves metabolic function in obese subjects. Obesity. 2014;22(9):2026-2031.

13. Woelnerhanssen B, Peterli R, Steinert RE, Peters T, Borbély Y, Beglinger $C$. Effects of postbariatric surgery weight loss on adipokines and metabolic parameters: comparison of laparoscopic Roux-en-Y gastric bypass and laparoscopic sleeve gastrectomy — a prospective randomized trial. Surg Obes Relat Dis. 2011;7(5):561-568.

14. Chondronikola M, Harris LL, Klein S. Bariatric surgery and type 2 diabetes: are there weight loss-independent therapeutic effects of upper gastrointestinal bypass?. J Intern Med. 2016;280(5):476-486.

15. Faucher P, Poitou C, Carette C, et al. Bariatric surgery in obese patients with type 1 diabetes: effects on weight loss and metabolic control. Obes Surg. 2016;26(10):2370-2378.

16. Leung M, Xie M, Durmush E, Leung DY, Wong VW. Weight loss with sleeve gastrectomy in obese type 2 diabetes mellitus: impact on cardiac function. Obes Surg. 2016;26(2):321-326. 
17. Liu SY, Wong SK, Lam CC, Yung MY, Kong AP, Ng EK. Long-term results on weight loss and diabetes remission after laparoscopic sleeve gastrectomy for a morbidly obese Chinese population. Obes Surg. 2015;25(10):1901-1908.

18. Hoogerboord M, Wiebe S, Klassen D, Ransom T, Ellsmere J. Laparoscopic sleeve gastrectomy: perioperative outcomes, weight loss and impact on type 2 diabetes mellitus over 2 years. Can J Surg. 2014; 57(2): 101

19. Reis CE, Alvarez-Leite JI, Bressan J, Alfenas RC. Role of bariatricmetabolic surgery in the treatment of obese type 2 diabetes with body mass index $<35 \mathrm{~kg} / \mathrm{m}^{2}$ : a literature review. Diabetes Technol Ther. 2012;14(4):365-372.

20. Chuang J, Zeller MH, Inge T, Crimmins N. Bariatric surgery for severe obesity in two adolescents with type 1 diabetes. Pediatrics. 2013;132(4):e1031-e1034.

21. To VT, Hüttl TP, Lang R, Piotrowski K, Parhofer KG. Changes in body weight, glucose homeostasis, lipid profiles, and metabolic syndrome after restrictive bariatric surgery. Exp Clin Endocrinol Diabetes. 2012;120(09):547-552.

22. Bawahab MA, Assiri AS, Maksoud WA, et al. Effects of weight reduction after sleeve gastrectomy on metabolic variables in Saudi obese subjects in Aseer Province of Kingdom of Saudi Arabia. Obes Surg. 2017;27(8):2005-2014.

23. Aldaqal SM, Sehlo MG. Self-esteem and quality of life in adolescents with extreme obesity in Saudi Arabia: the effect of weight loss after laparoscopic sleeve gastrectomy. Gen Hosp Psychiatry. 2013;35(3):259-264.
24. Al Kadi A, Siddiqui ZR, Malik AM, Al Naami M. Comparison of the efficacy of standard bariatric surgical procedures on Saudi population using the bariatric analysis and reporting outcome system. Saudi Med J. 2017;38(3):251-256.

25. Ahmed A, AlBuraikan D, ALMuqbil B, AlJohi W, Alanazi W, AlRasheed B. Readmissions and emergency department visits after bariatric surgery at Saudi Arabian Hospital: the rates, reasons, and risk factors. Obes Facts. 2017;10(5):432-443.

26. Cheng V, Kashyap SR, Schauer PR, Kirwan JP, McCrae KR. Restoration of glycemic control in patients with type 2 diabetes mellitus after bariatric surgery is associated with reduction in microparticles. Surg Obes Relat Dis. 2013;9(2):207-212.

27. Buchwald H, Estok R, Fahrbach K, et al. Weight and type 2 diabetes after bariatric surgery: systematic review and meta-analysis. Am J Med. 2009;122(3):248-256.

28. Dorman RB, Serrot FJ, Miller CJ, et al. Case-matched outcomes in bariatric surgery for treatment of type 2 diabetes in the morbidly obese patient. Ann Surg. 2012;255(2):287-293.

29. Diniz MD, Diniz MT, Sanches SR, et al. Glycemic control in diabetic patients after bariatric surgery. Obes Surg. 2004;14(8):1051-1055.

30. Tang Q, Sun Z, Zhang N, Xu G, Song P, Xu L, Tang W. Cost-effectiveness of bariatric surgery for type 2 diabetes mellitus: a randomized controlled trial in China. Medicine (Baltimore). 2016;95(20):e3522.

31. Cutolo PP, Nosso G, Vitolo G, Brancato V, Capaldo B, Angrisani L. Clinical efficacy of laparoscopic sleeve gastrectomy vs laparoscopic gastric bypass in obese type 2 diabetic patients: a retrospective comparison. Obes Surg. 2012;22(10):1535-1539.

\section{Publish your work in this journal}

Diabetes, Metabolic Syndrome and Obesity: Targets and Therapy is an international, peer-reviewed open-access journal committed to the rapid publication of the latest laboratory and clinical findings in the fields of diabetes, metabolic syndrome and obesity research. Original research, review, case reports, hypothesis formation, expert opinion and commentaries are all considered for publication. The manuscript management system is completely online and includes a very quick and fair peer-review system, which is all easy to use. Visit http://www.dovepress.com/testimonials.php to read real quotes from published authors. 